\title{
Names Style Sheet
}

Revised June 2004

All submissions to Names should be prepared according to the author-date system of documentation as found in The Chicago Manual of Style (15th ed., 2003, chap. 16). Documentation should be given in the text rather than in notes, with a list of references giving full bibliographic information following the text and notes. One paper copy and one electronic copy of articles as well as reviews, queries, notes, or comments should be submitted to the editor. If submitted through e-mail, electronic files should be sent only as attachments to e-mail, not in the body of the e-mail message text. The files should be either WORD, RTF, or text files. They should be sent to NAMES@geneseo.edu. If submitting by regular mail, the electronic files may be either on 3.5 inch floppy disks or CDs.

This style sheet assumes that manuscripts will be created and printed using a word processor or computer. Typewritten manuscripts are acceptable and should follow these guidelines also. For details and circumstances not covered here, see the appropriate sections in The Chicago Manual of Style.

Manuscripts of articles submitted to Names usually consist of a cover page, an abstract, the text of the article, notes, and references. These may be supplemented by appendices, maps, charts, tables, graphs, or figures.

\section{Manuscript}

A. On the cover page give the title and subtitle of the article and the complete name and affiliation, mailing address, e-mail address, FAX, and telephone number of the author(s). This information should be on the cover page and nowhere else.

B. In the abstract, characterize and summarize the article. Include such things as the nature of the issues considered, the sources of the data, the methodologies used, and a general summary of the findings. The abstract should be approximately 100-150 words and should be written in the same style and voice as the body of the article.

C. Prepare the text of the article and notes using the following guidelines. The first three items are especially important. 
1. Disable the hyphenation feature of your word processor.

2. DO NOT use the footnote/endnote feature of your word processor for notes. Type all notes AS TEXT following the body of your article directly before the list of references.

3. DO NOT use headers or footers or page numbers.

4. Use standard $81 / 2 \times 11$ inch paper (or A4) and leave 1-inch margins at the top and bottom and along each side.

5. Double space the manuscript throughout: title, abstract, text, quotations (no matter how long) and notes. The references section should be treated differently (see II. B. 9 below).

6. Quotations should be incorporated directly into the text whenever possible. However, quotations which would take up more than three lines should be set apart and indented from both the left and right margins approximately $1 / 2$ inch.

7. Print manuscripts in Times or Palatino or a comparable font. Avoid the temptation to use such highlighting features as shadow, redline, double underline, or small capitals. Use bold only in the single circumstance noted in item 9 below.

8. Italicize where italics would appear in print; for example, for book and journal titles or for emphasis. Italicize words, names, and phrases only when they are used as onomastic examples and incorporated directly into the text:

Vogel has found more than 30 spellings of the name Chicago, including chicogua, chekakou, and Eschikagou.

9. Citation forms and examples from foreign languages should be italicized and glosses enclosed in single quotation marks:

Istrouma 'red stick' is a familiar example.

Another such name is Edward, which means 'guardian.'

Place connotations of names in double quotation marks:

Mitchell "thoughtful and intelligent."

10. Consider lists of names accompanied by commentary as though they comprise a small name dictionary. These should be listed and discussed individually rather than in connected text. In these cases, treat each name and its commentary as a 
separate paragraph, bolding each name when it occurs as a citation form:

A number of names have disputed or incorrect etymologies:

Fair Dealing. The name may or may not have been derived from the practice of treating sympathizers of both the North and the South equally.

Berlin. The name of the city in Maryland has nothing to do with the city in Germany; rather, it is a contraction of Berle's Inn.

Balbo. The Chicago street name is not a misrepresentation of Balboa, as it might appear to the folk etymologist, but is named for an officer in the Italian Air Force.

\section{Documentation}

Normally the names of books, journals, or articles should not appear in the text. Documentation by author and date of publication should appear in reasonable proximity to the quotation or paraphrase it documents. Notes should be reserved for additional examples, explanations, elaborations, or qualifications of points made in the text. Notes, of course, may contain their own documentation.

\section{A. Internal (Parenthetical) Documentation}

1. Identify all references in parentheses by author and year of publication. Separate multiple references with semi-colons:

(Harder 1989). Or: (Miller 1987; Ashley 1989b).

2. For direct quotations and when otherwise relevant, include page number(s) in addition to author and year of publication:

Litt believes that "the placename Essex was excised either by the censor or by Shakespeare himself" $(1993,301)$. Or: (Rennick 1991, 3-4). Or: 
(Murray 1993a, 34; Nuessel 1990, 12, 21-32, 330-31).

3. If the author's name is included as part of the text, do not repeat it in the citation:

Nicolaisen (1993b) has noted the value of placenames in the study of language change. Or:

The value of placenames in the study of language change has been noted by Nicolaisen (1993b). Or:

Nicolaisen has noted the value of placenames in the study of language change (1993b).

B. References

Normally the reference section contains full bibliographic information on all and only those works explicitly mentioned in the body of the article or in the notes. Begin the reference section on a new page, but WITHOUT entering a hard page break in the document.

1. Treat each reference entry as a text block, using hanging indents, where the first line is aligned left and subsequent lines of each entry are indented.

2. Single-space within entries and double-space between entries, using the same typeface and size that you use in the body of the article and in the notes.

3. Include the following elements in each entry: author's surname, give name(s) or initial(s), and, if appropriate, the given name(s) and surname(s) of other authors followed by a period; then the year of publication, also followed by a period. Give the full title and subtitle of the work, italicized if it is a book, in double quotation marks if it is a journal article. Article titles should be followed by the full name of the journal, italicized, the volume number, a colon, and the page number(s). The titles of books should be followed by the place of publication and the name of the publisher (see sample entries below).

4. Arrange entries alphabetically by surname(s) of author(s).

5. Arrange multiple works by the same author(s) in ascending chronological order. 
6. Use lowercase letters to distinguish multiple items published by the same author(s) in the same year(s).

7. Use authors' names as they appear on the original publication; do not replace full names with initials or vice versa.

8. Do not abbreviate university press names.

Examples of entries in the reference section:

Allen, Irving Lewis. 1983a. The Language of Ethnic Conflict: Social Organization and Lexical Culture. New York: Columbia University Press.

1983b. "Personal Names That Became Ethnic Epithets." Names 31:307-17.

Barry, Herbert, III, and Aylene S. Harper. 1993. "Feminization of Unisex Names from 1960 to 1990." Names 41:228-238.

Grimaud, M. 1988. “Discourse Anaphora and the Functioning of Proper Names in Narrative." Psychological Approaches to the Study of Literary Narrative. Ed. Colin Martindale. Hamburg: Buske, 96-132.

1989. "Onomastics and the Study of Literature." Yearbook of Comparative and General Literature 38: 16-35.

Nicolaisen, W.F.H. 1976. Scottish Place-Names: Their Study and Significance. London: Batsford.

OED. Oxford English Dictionary. 1933. 12 vols. Oxford: Clarendon.

Read, Allen Walker. 1984. "Changes in the Place-Name Cover of the United States." North Central Name Society. Chicago, April.

Rennick, Robert M. 1984. Kentucky Place Names. Lexington: University Press of Kentucky. 
158 - NAMES 52:2 (June 2004)

III. Non-text Items

Figures, maps, charts, and other graphics should be professionally produced and sized to fill a space measuring no larger than $41 / 2$ by $61 / 4$ inches. Provide an appropriate descriptive title for each graphic and place each one on a separate numbered page.

Be sure that permission is granted to use any illustrations that are not created by the author(s) and submit said permission to the editor. 